\title{
Bcl-2 and Bax proteins are present in interphase nuclei of mammalian cells
}

RWM Hoetelmans ${ }^{1,3}$, H-J van Slooten ${ }^{1,3}$, R Keijzer', $S$ Erkeland ${ }^{1,2}, \mathrm{CJH}$ van de Velde ${ }^{1}$ and $\mathrm{JH}$ van Dierendonck ${ }^{\star, 1}$

${ }^{1}$ Department of Surgery, Leiden University Medical Center, Building 1, K6R, P0 Box 9600, 2300 RC Leiden, The Netherlands

${ }^{2}$ Current address: Department of Haematology, Erasmus University Rotterdam, The Netherlands

${ }^{3}$ Both authors contributed equally

* Corresponding author: Dept. of Surgery, Leiden University Medical Center, Building 1, K6R, Albinusdreef 2, P.0. Box 9600, 2300 RC Leiden, The Netherlands. Tel: +31-071-5262982; Fax: +31-071-5248238;

E-mail: dierendonc@surgery.azl.nl

Received 29.6.99; revised 17.12.99; accepted 17.1.00

Edited by D Vaux

\section{Abstract}

The Bcl-2 family of proteins comprises both cell death inhibiting and cell death promoting members, generally believed to be cytoplasmic and predominantly membraneassociated. Like $\mathrm{Bcl}-2$, many $\mathrm{Bcl}-2$-related proteins contain a C-terminal membrane insertion domain and much research is aimed at evaluating the functional role of their localization to the outer membranes of mitochondria, the endoplasmic reticulum, and perinuclear membranes. However, confocal fluorescence microscopy of human breast cancer cells and rat colon cancer cells immunostained with commercial antibodies raised against different epitopes of the anti-apoptotic $\mathrm{Bcl}-2$ and the pro-apoptotic Bax protein revealed that these proteins are not only present in the cellular cytoplasm, butalso within interphase nuclei. This was confirmed by Western blot analysis of isolated nuclei. In human cells, certain epitopes of $\mathrm{Bcl}-2$, but not of Bax, were also found to be associated with mitotic chromatin. Anti-estrogen treatment of human breast cancer cells or transfection with antisense bcl-2 led to a reduction in both cytoplasmic and nuclear $\mathrm{Bcl}-2$. Transfection of human bcl-2 and bax into rat cells resulted in cytoplasmic and nuclear Bcl-2 and Bax. This data seems in line with increasing evidence that the role of the $\mathrm{Bcl}-2$ family of proteins should be extended to activities inside the nuclear compartment. Cell Death and Differentiation (2000) 7, 384-392.

Keywords: Bcl-2; Bax; cellular nucleus; mitotic chromosomes; confocal immunofluorescence microscopy; cell fractionation

Abbreviations: $\mathrm{BC}$, breast cancer; $\mathrm{BSA}$, bovine serum albumine; $\mathrm{DAB}$, diaminobenzidine; $\mathrm{ER}$, endoplasmic reticulum; $\mathrm{FCS}$, fetal calf serum; FITC, fluorescein isothiocyanate; MAb, monoclonal antibody; PAb, polyclonal antibodies; PAGE, polyacrylamide gel electrophoresis; PARP, poly(ADPribose) polymerase; PBS, phosphate buffered saline; PI, propidium iodide; SDS, sodium dodecyl sulphate; TM, transmembrane

\section{Introduction}

The family of Bcl-2-related proteins constitutes an important class of either anti-apoptotic (e.g. Bcl-2, Bcl-X $\mathrm{L}$, Mcl-1, or Bclw) or pro-apoptotic (e.g., Bax, Bcl-Xs, Bak, Bad, Bik, Bid, Diva) gene products. ${ }^{1,2}$ Well-documented proteins in this family are Bcl-2 and Bax. Bcl-2, with a molecular weight of $\sim 26 \mathrm{kD}$, was originally identified at the breakpoint of the $t(14 ; 18)$ chromosomal translocation found in low-grade B-cell lymphomas, characterized by upregulation of $b c /-2$ gene expression and resistance towards induction of apoptotic cell death. $^{3,4}$ The structural homolog Bax was identified as a heterodimerizing partner inhibiting the anti-apoptotic function of $\mathrm{Bcl}-2{ }^{5}$ At present, the mechanisms of apoptosis regulation by $\mathrm{Bcl}-2$ and Bax remain unclear. Whereas dimerization seems important, the relevance of heterodimerization is still controversial as recent studies have revealed that both $\mathrm{Bcl}-2$ and Bax can act independently. ${ }^{6}$

Earlier immuno-electron microscopy studies described the presence of $\mathrm{Bcl}-2$ at multiple subcellular localizations, i.e., in nuclear outer membrane, ${ }^{7-13}$ endoplasmic reticulum membrane, ${ }^{10,11,13,14}$ and mitochondrial membranes. ${ }^{4,9,10,12,13}$ These findings seemed to be in accordance with the presence of a C-terminal stretch of 17 hydrophobic amino acids for targeting the protein to the cytoplasmic surface of multiple intracellular membranes. ${ }^{15}$ Constructs lacking this transmembrane (TM) domain are cytosolic, but were reported to retain some anti-apoptotic ability, ${ }^{6,16}$ although not in every condition. ${ }^{21}$ Also replacement of the TM segment by the corresponding domains of other proteins could fully protect against growth factor deprivation in certain, ${ }^{17,18}$ but not all, conditions. ${ }^{18}$

TM domains are present in the majority of $\mathrm{Bcl}-2$ related proteins, with exception of Bad, Bid and EGL-1. ${ }^{2}$ Recently, several research groups have described that monomeric Bax protein is diffusely present within the cytosol or peripherally associated with endocellular membrane surfaces. After exposure of cells to an apoptotic stimulus, i.e., after activation of caspases, Bax may undergo a conformational change and translocates to mitochondrial membranes. ${ }^{19-22}$ However, Bax was also reported to redistribute from the cytosol to a position inside nuclei, i.e. along the nuclear membranes. ${ }^{23-25}$

Elucidation of the 3-dimensional structure of $\mathrm{Bcl}-\mathrm{X}_{\mathrm{L}}$ revealed a striking similarity with the pore-forming domains of some types of bacterial toxins. ${ }^{26}$ Subsequent experiments showed that, under certain conditions, Bcl-2, Bcl- $\mathrm{X}_{\mathrm{L}}$ and Bax indeed form ion-channels in synthetic membranes. ${ }^{27}$ It has been hypothesized that this feature might be important in regulating the release of caspase activitytriggering factors from mitochondria and that the poreforming activity of Bax can be antagonized by $\mathrm{Bcl}-2 .^{28}$

Apart from dimerization with other Bcl-2 family members and membrane insertion, $\mathrm{Bcl}-2$ binds to an ever expanding list of non-homologous proteins, including the CED-4 
homolog Apaf-1, the protein kinase Raf-1, the $\mathrm{Ca}^{2+}$-activated calcineurin, the Hsp70 molecular chaperone regulator BAG1 , the p53 binding protein 53BP-2, the multiple membrane spanning protein $\mathrm{Bl}-1$, and the Adenine Nucleotide Translocator of the mitochondrial inner membrane, which also interacts with $\mathrm{Bax}^{2}$ Thus, the $\mathrm{Bcl}-2$ family is not only redundant in the ability of certain members to replace other members functionally, it is also becoming increasingly evident that certain members are multifunctional. In that context the identification of proteins like Bcl-2 and Bax in rather unexpected intracellular locations may not be surprising. In previous studies on immunohistochemical detection of $\mathrm{Bcl}-2$ in formalin-fixed paraffin-embedded breast cancer material we observed an exclusive cytoplasmatic staining pattern, ${ }^{29}$ with exception however of a small series of breast cancers preoperatively treated with chemotherapy in which we clearly observed intranuclear and mitotic chromosomes-associated staining patterns $(\mathrm{H} .-\mathrm{J}$. van Slooten, unpublished data). This observation seemed to be in line with two reports describing a transient association of $\mathrm{Bcl}-2$ to mitotic chromatin after staining mildly fixed epithelial cells with the same MAb\#124..$^{30,31}$ In addition, intranuclear and/or mitotic chromosomal immunostaining of $\mathrm{Bcl}-2$ with this antibody had been occasionally described in different tumor types, i.e. in endometrial cancer, ${ }^{32}$ chromophobic renal cell carcinoma, ${ }^{33}$ squamous cell carcinoma and astrocytoma. ${ }^{34}$ Recently, Schandle and coworkers reported further studies into the distribution of $\mathrm{Bcl}-2$ in various cell lines, demonstrating chromosomal labeling in cells from neoplastic as well as non-neoplastic origin. ${ }^{35}$ Moreover, in KB epidermal cancer cells, Western blots of isolated nuclei suggested the presence of a nuclear form of Bcl-2. ${ }^{36}$ However, the presence of $\mathrm{Bcl}-2$ inside interphase nuclei could not be confirmed with immunofluorescence microscopy.

The present study further substantiates these findings, addressing by the use of confocal immunofluorescence microscopy the subcellular localization of both $\mathrm{Bcl}-2$ and Bax in human breast cancer cells and rat colon cancer cells with a panel of different antibodies and by Western blot analysis of purified nuclear and cytoplasmic fractions. Modulation of cellular Bcl-2 levels and $b c /-2$ (sense and antisense) and bax gene transfection experiments were performed to confirm staining specificities. The present data allow the conclusion that the location of both $\mathrm{Bcl}-2$ and $\mathrm{Bax}$ is not restricted to cytosol and intracellular membranes, but that these proteins indeed may as well function within the nuclear compartment.

\section{Results}

\section{Variable nuclear antigenicity of Bcl-2 and Bax with a panel of commercial antibodies}

Indirect immunofluorescence staining was performed on monolayers of MCF-7 cells, using a panel of four commercial Bcl-2-specific MAbs (\#124, \#100, \#4D7, and \#6C8). Mild paraformaldehyde fixation and subsequent methanol permeabilization indicated that MAbs \#124 and \#100, both raised against the same synthetic peptide corresponding to amino acids $41-54$ of the $B c l-2$ protein, not only strongly stained $G_{2} / M$ cells, but, with somewhat variable intensity, also all interphase nuclei, while sparing intranuclear nucleoli-resembling areas (Figure $1 \mathrm{~A}, \mathrm{~B})$. Only application of MAb\#100 resulted in a speckled cytoplasmic staining pattern, possibly reflecting the presence of mitochondria (Figure 1B). In contrast, \#4D7 and $\# 6 \mathrm{C} 8$, respectively raised against amino acids $61-78$ and against the entire recombinant $\mathrm{Bcl}-2$ protein, did not immunostain $\mathrm{G}_{2} / \mathrm{M}$ cells, being in accordance with data presented by Schandle et al. ${ }^{36}$ Moreover, whereas \#4D7 produced a weak

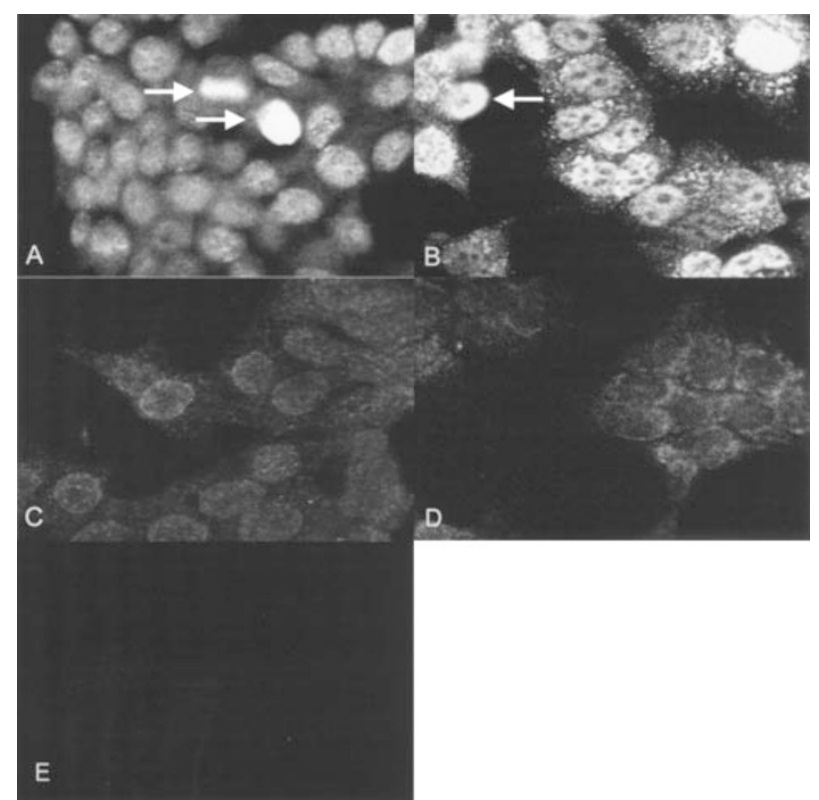

Figure 1 Confocal laserscan microscopy of MCF-7 cells: immunofluorescence detection of Bcl-2 by a panel of different antibodies. (A) MAb\#124 (B) MAb\#100. (C) MAb\#4D7. (D) MAb\#6C8. (E) Isotype specific control mouse $\lg \mathrm{G} 1$. Arrows in $A$ and $B$ indicate mitotic figures

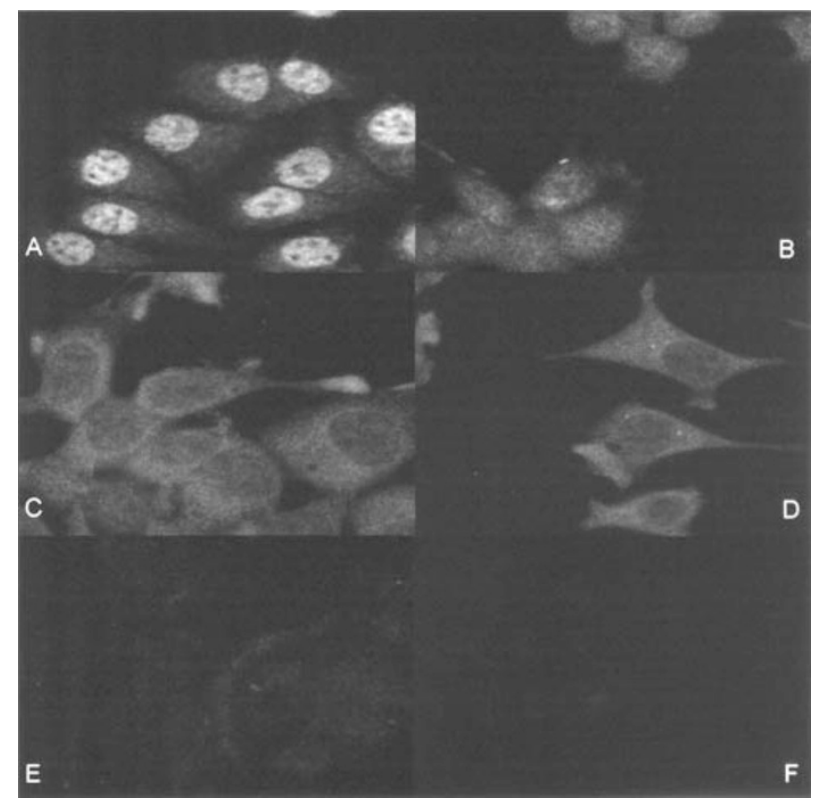

Figure 2 Confocal laserscan microscopy of images of MCF-7 cells: immunofluorescence of Bax detected with various different antibodies. (A) PAb 13666E. (B) MAb\#B-9. (C) MAb\#2D2. (D) MAb\#4F11. (E) Incubation with normal rabbit serum. (F) Isotype specific control mlgG2b 
nuclear staining (Figure 1C) the staining pattern of \#6C8 seemed to be almost exclusively cytoplasmic (Figure 1D).

Subsequently, we performed similar experiments with commercial antibodies against Bax protein: PAb13666E, MAbs \#B-9, \#4F11, and \#2D2. As shown in Figure 2, 13666E produced an intense nuclear staining (Figure $2 \mathrm{~A}$ ), whereas a weak nuclear staining was observed with \#B-9 (Figure 2B). Although \#4F11 and \#2D2 clearly stained the cytoplasm, a relatively faint nuclear staining was observed with these antibodies (Figure 2C,D respectively). Negative controls (isotype specific normal mouse $\operatorname{lgG}$ and normal rabbit $\lg G$ ) were completely negative. In contrast to the anti-Bcl-2 stainings, none of the anti-Bax antibodies interacted with mitotic figures and cytoplasmic stainings were very diffuse.

Staining of mitotic figures by anti-Bcl-2 antibodies, but not by anti-Bax antibodies was confirmed using double labeling with propidium iodide in confocal immunofluorescence microscopy (Figure $3 \mathrm{~A}$ ) and flow cytometric analysis (Figure 3B).

Next we isolated nuclear and cytoplasmic fractions from several human breast carcinoma cell lines (MCF-7, ZR-75-1, $\mathrm{BT}-474$, and RC-6) and the rat colon carcinoma cell line CC531 and performed Western blot analysis on these separate fractions. All above antibodies and PAbN-19 and PAb15616E rat Bcl-2 specific antibodies, as well as PAbN-20 anti-Bax antibodies, showed single characteristic bands i.e., a $26 \mathrm{kDa}$ band for human Bcl-2, a 24-26 kDa band for rat $\mathrm{Bcl}-2$, and a $21 \mathrm{kDa}$ band for both human and rat Bax.
These patterns were observed in both the nuclear and cytoplasmic fractions of all cell lines evaluated. As with the immunofluorescence stainings, strongest nuclear signals were obtained with MAbs \#100 and \#124 for Bcl-2 and PAb13666 for Bax. Figure 4 shows an example of MCF-7 cells stained with latter MAbs; purity of the two fractions was established by reactivity for PARP in nuclear and for caspase-3 in cytoplasmic fractions. ${ }^{23}$

Thus, although all antibodies tested seemed to detect nuclear epitopes, staining intensities showed profound differences. With respect to $\mathrm{Bcl}-2$, only the MAbs \#124 and \#100 directed against amino acids $41-54$ of the Bcl-2 protein were associated with staining of highly condensed mitotic chromatin. In addition, these two MAbs were also associated with strongly stained interphase nuclei. Unfortunately, above data did not rule out the possibility that, under the present fixation conditions that are responsible for the strong staining of condensed chromatin, MAb\#124 and $\# 100$ detect a crossreactive antigen. This prompted us to perform experiments that would unequivocally confirm the specificity of nuclear Bcl-2 and Bax immunostainings.

\section{Modulation of expression confirms specificity of Bcl-2 immunoreactivity}

We followed two different strategies to provide further evidence that both $\mathrm{Bcl}-2$ and Bax are indeed present in interphase nuclei: downregulation of endogenous $\mathrm{Bcl}-2$
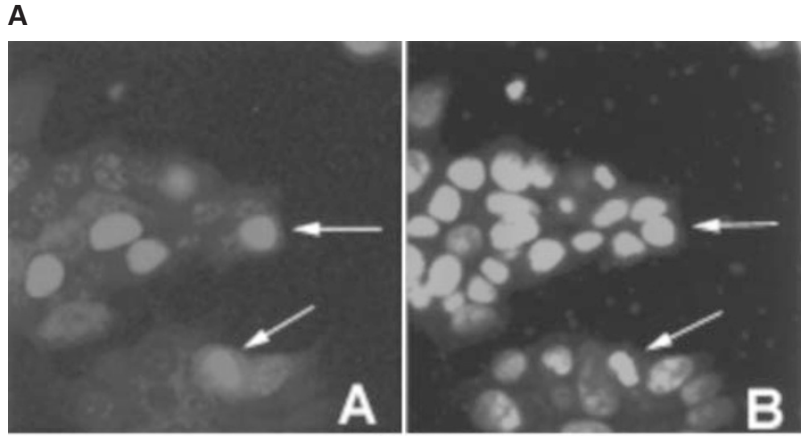

B
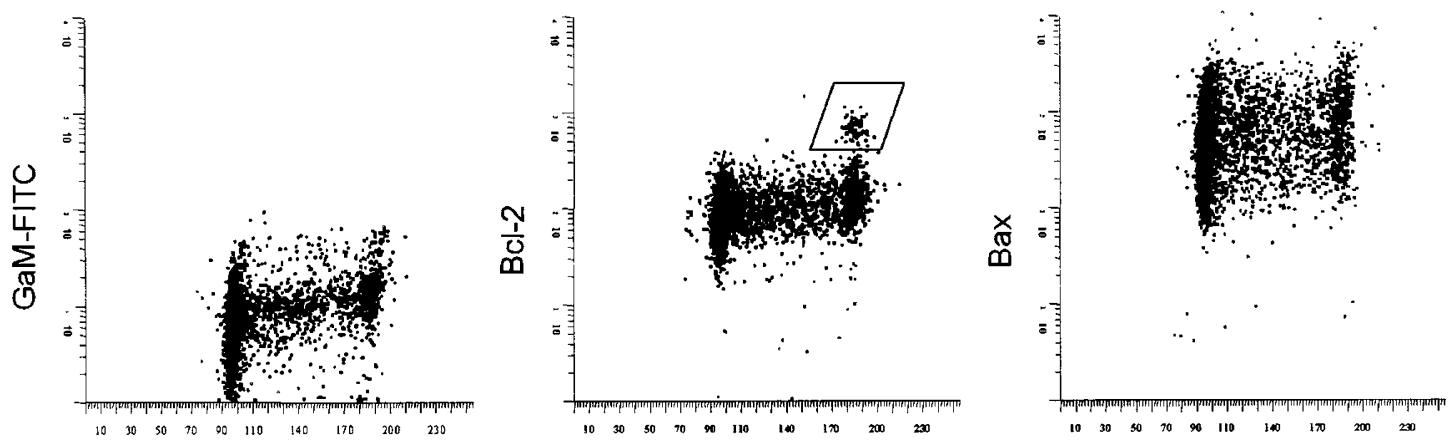

DNA-content

Figure 3 Confocal laserscan microscopy and flow cytometric diagram of MCF-7 cells stained with propidium iodide and Bcl-2 or Bax. (A) Top panel; double labeling for $\mathrm{Bcl}-2(\mathrm{~A} ; \# 100)$ and DNA (B; PI) are shown separately and arrows point at two mitotic cells extensively labeled for Bcl-2 and PI. (B) Dual-parameter flow cytometric histogram of MCF-7 human breast cancer cells stained with propidium iodide (DNA content) and isotype-specific control (mouse Mabs, left panel), Bcl-2 (MAb\#124) mid panel) or Bax (MAb\#2D2, right panel) detected with FITC-labeled secondary antibodies. Square: a distinct population of cells relatively strongly positive for Bcl-2 within the $G_{2} / M$ fraction. Note: no such a population is detected in Bax stained cells 
expression in MCF-7 cells and transfection of human $\mathrm{Bcl}-2$ and human Bax into rat cells and staining with antibodies not crossreacting with rat protein.

Downregulation of cellular Bcl-2 levels was accomplished by two different approaches. First, we stably transfected MCF-7 cells with the bcl-2 gene in antisense orientation. Verification of this antisense position was accomplished by a single sequencing reaction. Neomycinresistant MCF-7 single-cell colonies were screened for $\mathrm{Bcl}-$ 2 expression by Western blot analysis with MAb\#100 (Figure 5, top panel). From a number of clones displaying equal amounts of $\beta$-actin we selected a clone (A3) that was completely negative for $\mathrm{Bcl}-2$ expression on Western blot. When these cells were analyzed with confocal immunofluorescence microscopy, no nuclear or cytoplasmic immunoreactivity for $\mathrm{Bcl}-2$ was found (Figure 6). However, a relatively faint mitotic chromatin staining was still observed (Figure 6B, arrow), suggesting that although $\mathrm{Bcl}-2$ was reduced to a level at which no cytoplasmic or nuclear immunostaining was observed, some residual $\mathrm{Bcl}-2$ could be responsible for $G_{2} / M$ phase staining.

We and others found that in human breast cancer a strong correlation exists between high expression of $\mathrm{Bcl}-2$ and the presence of estrogen receptors ${ }^{29}$ and that estrogen induces expression of Bcl-2 in the hormone-responsive MCF-7 cells, whereas this expression is significantly reduced during treatment with antiestrogens. ${ }^{37}$ Previous experiments revealed that treatment with compounds like Tamoxifen or ICl164.384, after a period of 6 days results in an up to tenfold reduction of $b c l-2$ mRNA (J.H. Van Dierendonck, unpublished data). In the present study we treated MCF-7 cells for 6 days with $10^{-6} \mathrm{M}$ of the antiestrogenic compound $\mathrm{ICl}-182.780$. This treatment resulted in a marked reduction of cell proliferative activity (not shown) and Bcl-2 protein levels (Figure 5, lower panel). As illustrated in Figure 6, a commensurate reduction of both cytoplasmic and nuclear $\mathrm{Bcl}-2$ immunofluorescence staining levels was observed. Because of the dramatic reduction in cell cycling activity we were not able to verify whether also in this experiment the intensity of mitotic staining was reduced compared to untreated controls.

\section{Intranuclear presence of human $\mathrm{Bcl}-2$ and $\mathrm{Bax}$ in rat cells after gene transfection}

In another series of experiments, we introduced the human bcl-2 and bax genes in the CC531 rat colon carcinoma cell
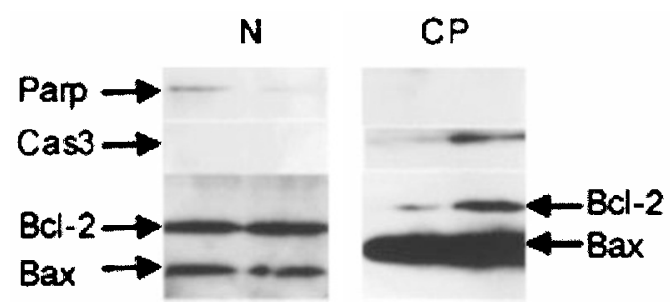

Figure 4 Western blot analysis of $\mathrm{Bcl}-2$ and $\mathrm{Bax}$ in nuclear and cytoplasmic fractions of MCF-7 cells. Nuclear (N) and cytoplasmic (CP) fractions were screened for PARP (113 kDa), caspase 3 (cas3; $32 \mathrm{kDa}), \mathrm{Bcl}-2$ (26 kDa), and Bax $(21 \mathrm{kDa})$ with respectively MAbs\#C-2-10, \#19, \#100, and PAb $13666 \mathrm{E}$. Stainings for $\mathrm{Bcl}-2$ and $\mathrm{Bax}$, and PARP and caspase 3 respectively were performed simultaneously (multiple antigen detection) line and determined their subcellular localization with MAbs \#100 (Bcl-2) and \#2D2 (Bax). These MAbs do not crossreact with rat $\mathrm{Bcl}-2$ or rat $\mathrm{Bax}$ and therefore allowed us to specifically determine the localization of the introduced human $\mathrm{Bcl}-2$ and Bax proteins. Transient expression of $\mathrm{bcl}-$ 2 resulted in a strong perinuclear localization of the gene product 2 days after transfection (Figure 7A). Following transient expression of bax we observed a clear presence of Bax protein within the nucleus at this time interval (Figure 7E). However, when cells were evaluated at 5 days after transient $b c /-2$ transfection the localization of $\mathrm{Bcl}-2$ had shifted from perinuclear to largely intranuclear (Figure 7B). This finding suggested that localization of $\mathrm{Bcl}-2$ to the
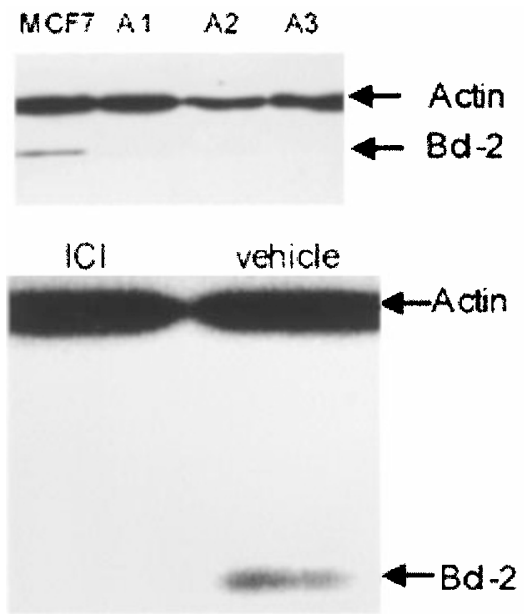

Figure 5 Western blot analysis of MCF-7 cells transfected with antisense $b c /$ 2 and MCF-7 cells treated with the pure antiestrogenic compound ICl-182.780. The top panel shows the Western blot analysis of the MCF-7 parental cell line (MCF7) and three antisense transfected cell lines (A1, A2, and A3). The lower panel shows MCF-7 cells treated with ICl-182.780 (left) or vehicle (right). $\beta$ actin protein levels show equal loading on all lanes

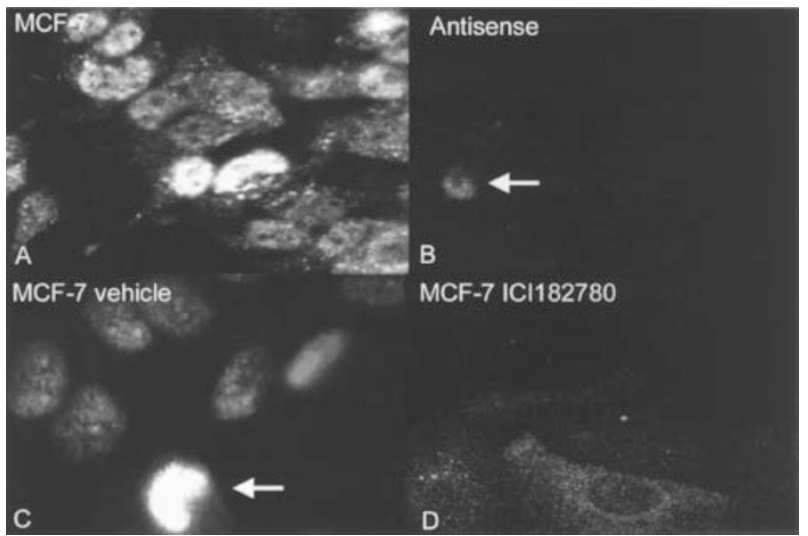

Figure 6 Confocal images of Bcl-2 immunofluorescence staining on MCF-7 cells transfected with antisense $b c l-2$ and MCF-7 cells subjected to vehicle- or anti-estrogen treatment. Images (A and $\mathbf{B}$ ) refer to the antisense $b c /-2$ experiment (arrow points at mitotic cell), images ( $\mathbf{C}$ and $\mathbf{D})$ display fluorescence staining on MCF-7 cells treated with vehicle or ICl-182.780. Contrast/brightness enhancement of image displaying MCF-7 cells treated with ICl182.780 was needed to visualize the low level of nuclear and cytoplasmic $\mathrm{Bcl}-2$ staining. MAb\#100 was applied to observe expression of $\mathrm{Bcl}-2$ in parental and antisense bcl-2 cells; MAb\#124 was used for staining of vehicle and $\mathrm{ICl}-182.780$ treated cells 
nucleus was time- and cell cycle dependent. To test this hypothesis, we subsequently selected CC531 cells stably transfected with human bcl-2 or bax genes. Figure $7 \mathrm{C}$ demonstrates a strong immunofluorescence reactivity of MAb\#100, both in the cytoplasm and in the nucleus. Notably, no Bcl-2 positively stained mitotic figures were observed in these rat cells, neither when stained for human Bcl-2 nor for endogenous rat Bcl-2 (not shown). Parental and neo-transfected cells did not show any immunoreactivity with this MAb\#100 (Figure 7D).

In CC531 cells stably transfected with the human bax gene, immunofluorescence with MAb\#2D2 revealed a strong punctate, primarily cytoplasmic staining pattern and a weak granular intranuclear localization (Figure 7F). Neobax transfected control cells displayed a very low background staining, lacking any resemblance with the staining pattern in bax transfectants (Figure 7G). Clearly, this image markedly differs from (i) the $\mathrm{Bcl}-2$ staining pattern in $\mathrm{Bcl}-2$ overexpressing rat cells, (ii) the Bax staining patterns observed in human cells, and (iii) the staining pattern in transient human bax transfectants. A possible explanation for these different staining patterns is that CC531 cells do not tolerate high nuclear levels of human Bax and, as a result, die after transfection, unless they are capable of excluding Bax from the nucleus.

As illustrated in Figure 8, after separation of nuclear and cytoplasmic fractions of the Bcl-2 overexpressing CC531 cells, Western blot analysis confirmed human Bcl-2 to be detectable in both fractions. A similar analysis on stable Bax transfectant revealed a very strong expression of human Bax protein, the vast majority residing in the cytoplasm.

\section{$\mathrm{Bcl}-2$ resides in the nucleoplasm}

Although confocal imaging provided reliable evidence for localization of $\mathrm{Bcl}-2$ (and Bax) inside interphase nuclei, we wanted to obtain additional evidence for the localization of $\mathrm{Bcl}-$ 2 inside the nucleoplasm. We obtained freshly-isolated rat hepatocytes for cell fractionation experiments as this cell type is well-described in yielding purified nucleoplasm and nuclear membrane fractions with a relatively simple technical procedure. ${ }^{38}$ Western blot analysis, with polyclonal antibodies against rat $\mathrm{Bcl}-2$, detected presence of a protein with a weight of $24-26 \mathrm{kDa}$ in cytoplasmic, nuclear (membrane) and nucleoplasm fractions (Figure 9A). This finding supports the confocal IF data showing intranuclear localization of Bcl-2 and additionally sustained the often-described association of $\mathrm{Bcl}-2$ with nuclear membranes. In order to highlight this membraneous localization, we compared the intracellular localization of Bcl-2 following IF staining with the immuno-reactivity of the nuclear pore complex-lamins fraction. Though these proteins are observed occasionally as intranuclear spots, ${ }^{39}$ their expression is primarily and strongly associated with the nuclear membrane as depicted in Figure 9B. Staining pattern of Bcl-2 was not distinguishably located near or attached to the nuclear surface as observed for the lamins staining.

\section{Discussion}

It is generally believed that $\mathrm{Bcl}-2$ and $\mathrm{Bax}$ are predominantly localized in the cellular cytoplasm. Our present data, for the first time, visualize nuclear localization of $\mathrm{Bcl}-2$ and $\mathrm{Bax}$ in interphase nuclei with the use of confocal laserscan microscopy. These data validate earlier observations by our group and by other investigators that both proteins also reside in the nucleus. The nuclear localization of $\mathrm{Bcl}-2$ is most clearly visible with the use of antibodies recognizing epitopes in amino acids $41-54$, residing within the flexible loop region of the protein. Transfection of human bcl-2 into CC531 rat cells revealed that at $48 \mathrm{~h}$ the majority of $\mathrm{Bcl}-2$ was detectable in the cytoplasm, whereas after 5 days it was mainly nuclear. This indicates that nuclear accumulation of $\mathrm{Bcl}-2$ is a relatively slow process and that the mild fixation and permeabilization procedure itself could not be held responsible for the observed $\mathrm{Bcl}-2$ relocalization. ${ }^{40}$

It is surprising that although $\mathrm{Bcl}-2$ has been studied extensively over the past decade, almost all available reports demonstrate that $\mathrm{Bcl}-2$ has a perinuclear and cytoplasmic localization. Only few reports addressed the possibility that $\mathrm{Bcl}-2$ is also localized in the nucleus in line with the presence of a transmembrane domain. It had been noticed in a variety of cell lines that certain $\mathrm{Bcl}-2$ epitopes are fully exposed during $\mathrm{G}_{2} / \mathrm{M}$ phase of the cell cycle, with a rapid disappearance of stainability in the transition from

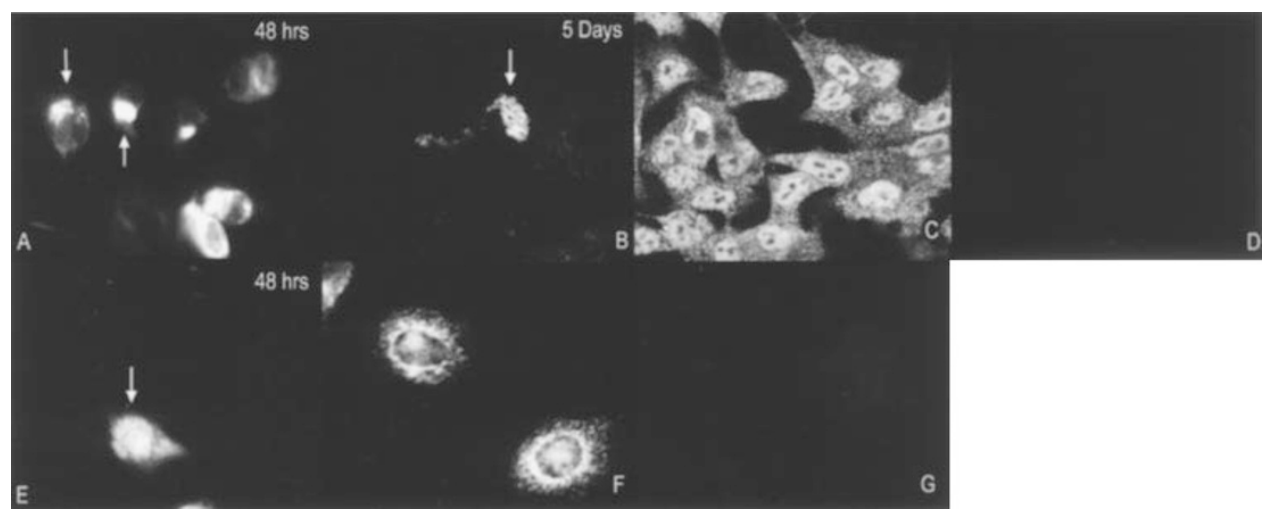

Figure 7 Confocal laserscan microscopy of CC531 rat coloncarcinoma cells transfected with human Bcl-2 or Bax, detected with MAb\#100 and MAb\#2D2 respectively. (A) CC531 cells $48 \mathrm{~h}$ after transfection with human $b c l-2$. (B) Five days after $b c l-2$ transfection. (C) CC531 cells stably transfected with $b c /-2$ (CCBcl2). (D) Neo-transfected control cell line (CC-neobcl2). (E) CC531 cells $48 \mathrm{~h}$ after transfection with human bax. (F) CC531 cells stably transfected with bax (CCBax). (G) Neomycin gene-transfected control cell line (CC-neobax) 


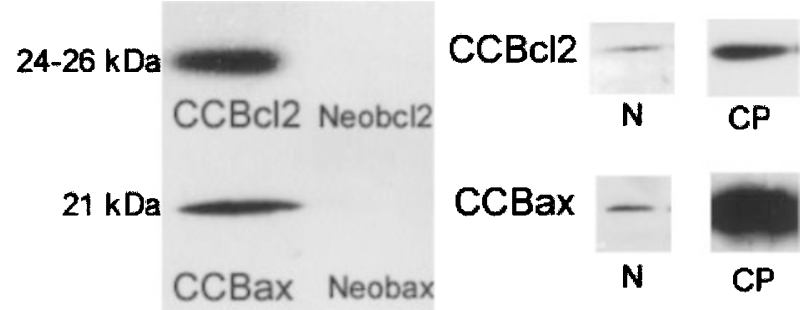

Figure 8 Western blot analysis for expression of human $\mathrm{Bcl}-2$ and human Bax, applying respectively clone 100 and clone 2D2. Depicted are bands visualized in whole cell lysates of CCBcl-2 and CCBax cells and their control neo-transfected cells (left panel) and the separated nuclear and cytoplasmic fractions of $\mathrm{CCBcl}-2$ and $\mathrm{CCBax}$ cells (right panel)
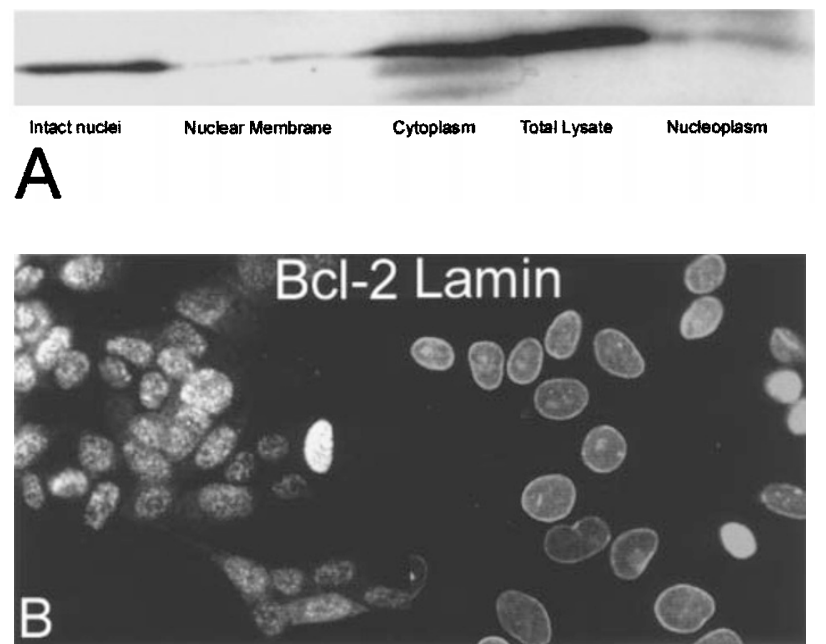

Figure 9 Western blot analysis for expression of rat $\mathrm{Bcl}-2$ in hepatocyte nucleoplasm and nuclear membrane fractions and confocal laserscan microscopy of MCF-7 cells stained for Bcl-2 and nuclear-membraneassociated lamins. (A) Specific 24-26 kDa bands for Bcl-2 were detected in following fractions: whole nuclei, nucleospasm, cytoplasm, total cell lysate, and fraction of nuclear membranes of in-vivo isolated rat hepatocytes. (B) MCF-7 cells stained for Bcl-2 (\#100; left image) or stained for lamins (right image)

anaphase to telophase..$^{30,31,36}$ Recently, data from immunoblots of subcellular fractions of $\mathrm{KB}$ cells suggested that $\mathrm{Bcl}-2$ is mainly present in the nuclear fraction. The authors hypothesized that in interphase nuclei, Bcl-2 may interact with other proteins in a way precluding interactions between the loop region and MAb\#124 or MAb\#100, but that during $\mathrm{G}_{2} / \mathrm{M}$ phase this epitope may become accessible. ${ }^{36}$ Because the detection of nuclear Bcl-2 depends on very mild fixation conditions (R.W.M. Hoetelmans, manuscript in preparation), one explanation could be that this hypothetical epitope-sheltering interaction of $\mathrm{Bcl}-2$ with nuclear components is stabilized by neutral buffered formalin. It should be noted though that prolonged formalin fixation not only diminishes immunostaining of interphase nuclei, but in addition strongly reduces staining of $\mathrm{G}_{2} / \mathrm{M}$ cells.

A remarkable finding was that although human $\mathrm{Bcl}-2$ was readily detected in interphase nuclei of rat cells, no mitotic chromatin-associated $\mathrm{Bcl}-2$ was detectable in these cells. Of interest in this respect is that also in CC531 cells no mitotic staining of endogenous rat $\mathrm{Bcl}-2$ occurs and that the staining pattern of human $\mathrm{Bcl}-2$ therefore mimics that of rat $\mathrm{Bcl}-2$. This would imply either that, in contrast to detection of Bcl-2 in interphase nuclei, mitotic immunostaining is not specific, or that in human cells, but not in rat cells, during $G_{2}$ phase of the cell cycle a change in antigenicity occurs that leads to enhanced immunostaining, while in rat cells this change in antigenicity does not occur. As we found that $b c l-2$ anti-sense treatment markedly reduced both nuclear and mitotic staining, this would support the second possibility. In that context it is interesting that during $\mathrm{G}_{2} / \mathrm{M}$ phase, $\mathrm{Bcl}-2$ has been reported to undergo hyperphosphorylation at serine residues, notably within the loop region, and that dephosphorylation occurs during telophase. ${ }^{41,42}$ If this mitotic phosphorylation is indeed responsible for elevated antigenicity, it is tempting to speculate that CC531 rat cells simply do not modify human $\mathrm{Bcl}-2$ as well as rat $\mathrm{Bcl}-2$ in that respect.

It has been suggested that nuclear/mitotic presence of $\mathrm{Bcl}-2$ could be related to malignant transformation. ${ }^{35,43}$ However, Schandle et al described chromosomal labeling of Bcl-2 in normal fibroblasts and amniocytes. ${ }^{36}$ In this study we present immunoreactivity of Bcl-2 in purified nucleoplasm and nuclear membrane fractions from freshly obtained rat hepatocytes. Thus, the nuclear presence of Bcl-2 does not seem to be restricted to a malignant phenotype.

Like Bcl-2, both immunocytochemistry and Western blotting experiments revealed a nuclear presence of Bax. However, we were unable to stain mitotic chromosomes with Bax antibodies. One explanation for this finding is that, at least during mitosis, Bcl-2 and Bax do not interact, possibly because association of $\mathrm{Bcl}-2$ with chromatin and/or $\mathrm{Bcl}-2$ hyperphosphorylation prevents binding to Bax. In this context it seems worth mentioning that in KB cells, immunoprecipitation with MAb\#124 following Western blots using anti-Bax had not provided any evidence for Bcl-2-Bax complex formation. $^{36}$

Whereas staining with anti-Bcl-2 antibodies tended to reveal punctate cytoplasmatic pattern, probably reflecting mitochondrial localization, this pattern was virtually absent when cells were stained with anti-Bax antibodies. This observation is in line with recent reports that Bax can adapt two different conformations, one of which is targeted to membranes, ${ }^{24-26}$ only after certain death stimuli, cytosolic Bax monomers will translocate to membranes, dimerize, and possibly form ion channels. However, at least two recent reports have provided circumstantial evidence that, following a death signal, Bax can also translocate to the cellular nucleus. In colorectal cancer cells, inhibition of signaling via the epidermal growth factor receptor led to enhanced expression of Bax, redistribution of the protein from the cytosol to inner side of the nuclear membrane, and apoptosis. $^{26}$ In a study on immortalized rodent fibroblasts transfected with the promyelocytic leukemia (PML) gene, Bax and the cyclin-dependent kinase inhibitor $p 27^{\text {kip1 }}$ initially were reported to be recruited to special nuclear matrixassociated structures ('PML nuclear bodies') prior to the induction of what appeared to be a caspase-independent type of cell death. ${ }^{44}$ However, the authors recently reported crossreactivity of the anti-Bax antibody SC I-19 with SP100, one of the components of PML bodies. ${ }^{45}$

In the context of our findings it is intriguing that nuclear localization of adenovirus E1B, a protein functionally and 
structurally related to $\mathrm{Bcl}-2$, seems to be an absolute requirement for its anti-apoptotic activity. ${ }^{46}$ However, there is an increasing awareness that many proteins have distinct roles in more than one cellular compartment and the presence of $\mathrm{Bcl}-2$ and $\mathrm{Bax}$ in interphase nuclei may therefore not necessarily be related to a functioning of these proteins in the process of cell death. E.g., evidence exists that high levels of Bcl-2 delay the transition of cells from a resting or G1 phase into S-phase, ${ }^{47-49}$ whereas Bax may accelerate this transition. ${ }^{50}$ But even within the nuclear compartment a further subcompartmentalization may occur as these proteins may locate to nuclear membranes, to chromatin, or just 'freely' traffic within the nucleoplasm. As was shown in Figure 7, the nuclear Bcl-2 staining pattern we observed for human $\mathrm{Bcl}-2$ overexpressing CC531 cells was markedly different from Bax in Bax overexpressing CC531 cells. Because Bax overexpression normally leads to apoptosis, one may speculate that CC531 cells selected for survival effectively neutralize this apoptosis-inducing property of Bax, either by direct inactivation of its function, e.g. by binding to specific inhibitors, or by preventing translocation of Bax to the nucleus.

An important question remains how $\mathrm{Bcl}-2$ and $\mathrm{Bax}$, which both lack a nuclear localization signal, enter the nucleus. At least for $\mathrm{Bcl}-2$ we cannot exclude the possibility that it does not enter the nucleus at all, but rather binds to chromatin during mitosis. This would explain why 2 days after transfection of human bcl-2 in CC531 cells we could not detect clear Bcl-2 positive nuclei: cells would first need to disassemble their nuclear membrane and, in addition, cells overexpressing $\mathrm{Bcl}-2$ may have had a reduced tendency to enter mitosis. Alternatively, Bcl-2 (and Bax) may simply 'hitch a ride' into the nucleus by binding to proteins that do have a nuclear translocation sequence. For instance, one isoform of the $\mathrm{Bcl}-2$ binding chaperone protein BAG-1, BAG$1 \mathrm{~L}$, has recently been reported to contain such a sequence, that preferentially targets it to the nucleus. ${ }^{51}$ Moreover, another Bcl-2 binding partner, calmodulin, has been found in the nucleus of many cell types and is probably imported via a facilitated transport mechanism. ${ }^{52}$

In conclusion, although many questions remain unanswered, the consistent finding following Western blot and immunofluorescence detection that $\mathrm{Bcl}-2$ and $\mathrm{Bax}$ reside in interphase nuclei of several cell lines tested strongly confirms the suggestive evidence provided by recent reports that the activity range of $\mathrm{Bcl}-2$ family members should be extended to the nuclear compartment of mammalian cells. Further research is needed to elucidate the significance of these nuclear forms in the regulation of cell death, survival, and/or cell cycle progression.

\section{Materials and Methods}

\section{Plasmids}

The full length $b c l-2$ gene (kindly provided by Dr. Stanley J. Kormeyer, St. Louis, MO, USA) was excised from the pBKKS vector and subcloned in the EcoR1 site of the pcDNA vector (Invitrogen) in sense or antisense orientation. Vector construction was verified by double enzyme digestion at specific sites and identification on $1 \%$ agarose gel. Plasmids were grown in $\mathrm{DH} 5 \alpha$ bacteria and plasmid DNA was extracted and purified (Maxiprep, Jetsorb) according to manufacturer's instructions. Constructs were sequenced (BaseClear, Leiden, The Netherlands). The $\mathrm{pCl}$-neo vector containing the 600 bp human bax cDNA was kindly provided by Dr. Wei Zhang, Houston, Texas.

\section{Cell lines}

Human breast cancer cell lines were maintained in Dulbecco's Modified Eagle Medium (DMEM) supplemented with 10\% FCS and 1\% L-glutamine at $37^{\circ} \mathrm{C}$ in an humidified incubator containing $5 \% \mathrm{CO}_{2}$. CC531 rat colon carcinoma cells were maintained in RPMI-1640 Dutch Modification under the same conditions as described above. Stably transfected cells were kept under $200 \mu \mathrm{g} / \mathrm{ml}$ neomycin. All reagents were purchased from Life Technologies.

\section{Transfection}

MCF-7 cells were stably transfected with the $b c l-2$ gene in antisense orientation, CC531 cells were transiently and stably transfected with the pcDNAbcl2 or pClbax construct and neoplasmids, all under pCMV promotor. Cells were grown on coverslips and were transfected at $50 \%$ confluency with the liposomal transfection reagent Fugene (Boehringer Mannheim) according to manufacturer's instructions. Cells were exposed to increasing concentrations of neomycin (MCF-7) or were kept under constant addition of $500 \mu \mathrm{g} / \mathrm{ml}$ (CC531) to generate stable transfectants. Neomycin-resistant single cells were picked and grown to monoclonal sublines. A second batch CC531 cells was transfected and kept in medium without addition of neomycin for several days for transient transfection.

\section{Antibodies}

For detection of human Bcl-2 we used murine MAbs raised against a synthetic peptide corresponding to amino acids 41-54 (MAb\#124: Boehringer Mannheim; MAb\#100: Pharmingen), MAb raised against amino acids 61-76 (MAb\#4D7: Pharmingen) and a hamster MAb directed to the entire protein (MAb\#6C8: Pharmingen). MAbs IgG1 or IgG2b (Dako) were used as isotype-specific negative controls. Fluorescein isothiocyanate (FITC)-labeled isotype-specific, goat antimouse antibody (GAM-FITC; DAKO) was directed to MAbs\#124, \#100, and \#4D7. A commercially available cocktail of FITC-labeled goat antihamster antibodies was used for recognition of MAb\#6C8. Rat Bcl-2 was detected applying the PAb N-19 (Santa Cruz Biotechnology) raised to amino acids $4-21$ or PAb 15616E (Pharmingen) raised to amino acids 68-86. For detection of human Bax we applied MAb\#4F11 (Immunotech) and MAb\#2D2 (Zymed) both raised against $\mathrm{N}$-terminus located portions of the Bax protein, MAb\#B-9 (Santa Cruz Biotechnology) directed to amino acids 1-171 and PAb 13666E (Pharmingen), raised to amino acids 43-61. Rat Bax was identified on blot by PAb N-20 (Santa Cruz Biotechnology) raised to amino acids 11-30. Additionally, MAb\#C4 (Boehringer Mannheim), MAb\#19 (Transduction Labs) and MAb\#C-2-10 (Oncogene) were applied to detect respectively $\beta$-actin, caspase- 3 and PARP. To detect the human nuclear-pore complex containing lamins $\mathrm{A}, \mathrm{B} 1, \mathrm{~B} 2$, and $\mathrm{C}$, a multi-epitope cocktail of mouse IgG1 Mabs was used (X67, X167, X233; Progen Biotechnik, Heidelberg, Germany).

\section{Immunofluorescent detection}

Cells were grown in chamberslides (Life Technologies), washed three times in PBS and fixed in freshly prepared $1 \%$ paraformaldehyde for $10 \mathrm{~min}$. To block free aldehyde groups, cells were treated with 
quenching buffer (0.05 M glycine in PBS/1\% BSA) for $15 \mathrm{~min}$. After washing twice in PBS/BSA, cells were permeabilized in cold $\left(-20^{\circ} \mathrm{C}\right)$ methanol for $10 \mathrm{~min}$ and reaction was blocked with PBS/BSA. Cells were pre-incubated in $5 \%$ normal goat serum (NGS) in PBS/BSA and incubated for $30 \mathrm{~min}$ at room temperature with primary antibody diluted in PBS/BSA/10\% NGS. Following washing in PBS/BSA, cells were incubated with GAM-FITC $(1: 50)$ or SWAR-FITC $(1: 20)$. Cells were washed and embedded in 2.5\% 1,4-diazabicyclo-octane (DABCO) in glycerol (both purchased from Sigma). Throughout all experiments antibodies were diluted as follows: isotype-specific controls 1:10; normal rabbit serum NRS 1:100, MAb\#100 1:50; MAb\#4F11 1:25; MAb\#B-9 and PAb 13666E 1:100; MAb\#4D7, MAb\#6C8 and MAb\#124 1:10. When exposed to MCF-7 cells, MAb\#2D2 was diluted $1: 25$ and 1:100 in case of rat cells. For dual staining with $\mathrm{PI}$, cells were treated with RNAse A (Sigma) for 30 min at $37^{\circ} \mathrm{C}$ and after extensive washing, cells were incubated with $0.01 \mu \mathrm{g} /$ $\mathrm{ml} \mathrm{PI}$ for 30 min on ice (Sigma).

\section{Microscopy}

Subcellular localization patterns of $\mathrm{Bcl}-2$ and $\mathrm{Bax}$ were visualized by the MRC-600 confocal laserscan microscopy system (BioRad) equipped with an argon laser (excitation line FITC $488 \mathrm{~nm}$ ) combined with the Zeiss image analysis program Zeiss Vision KS400. Per image, seven optical scans were combined (Kalman filter) under similar conditions concerning exposure time, laser strength (30\%) and magnification (640 times).

\section{Hormonal treatment of MCF-7 cells}

MCF-7 cells grown under standard conditions for 2 days, were subsequently treated for 6 days with vehicle $\left(70 \%\right.$ ethanol) or $10^{-6} \mathrm{M}$ of the antiestrogenic compound $\mathrm{ICl}-182.780$ (Zeneca). At day $6, \mathrm{Bcl}-2$ protein level (Western blotting) and subcellular distribution (immunofluorescence staining) was determined with MAb\#124.1

\section{Isolation of nuclei from cell lines}

Subconfluent cultures of MCF-7 and CC531 cells were harvested and pelleted at 1250 r.p.m. Cells were lysed by resuspension in ice-cold

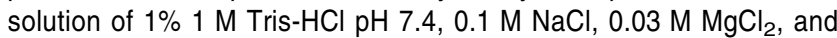
$0.5 \%$ Nonidet P40. Nuclei were pelleted at 2500 r.p.m. for $10 \mathrm{~min}$ at $4^{\circ} \mathrm{C}$. Supernatant (cytoplasmic fraction) was removed and $0.1 \mathrm{M}$ phenylmethylsulfonylfluoride (PMSF) and $1 \mathrm{mg} / \mathrm{ml}$ leupeptin (both from Sigma) were added. Nuclear pellets were resuspended in $1 \mathrm{M}$ Tris- $\mathrm{HCl} \mathrm{pH} \mathrm{7.4,} 50 \mathrm{mM}$ EDTA, $500 \mathrm{mM} \mathrm{NaCl}, 1 \mathrm{mg} / \mathrm{ml}$ leupeptin and $0.1 \mathrm{M}$ PMSF. Both fractions were pelleted at 2500 r.p.m. and were lightmicroscopically identified using Trypan Blue staining. Nuclear fractions were subsequently sonificated by three cycles of $10 \mathrm{~s}$.

\section{Isolation of nuclear fractions of rat hepatocytes}

Hepatocyte isolation was performed using a modification of the Seglen collagenase digestion technique. ${ }^{53}$ Briefly, rat liver was perfused with HEPES containing collagenase B. Following digestion, the liver was excised, the capsule removed to wash and filter the suspension of hepatocytes. Isolation of nuclei was performed as described for rat CC531 cells. As described by Graham ${ }^{38}$ one part of the nuclear pellet was resuspended in Tris/sucrose/Triton X-100. After centrifugation, the pellet was resuspended in Tris/sucrose and sonificated. The sample was centrifuged through a sucrose gradient resulting in supernatant containing nucleoplasm and a remaining pellet of nuclear membrane fragments.

\section{Western blot detection of $\mathrm{Bcl}-2$ and Bax}

Detectable amounts of protein (Bradford assay) per lane were prepared and resolved by denaturing SDS-PAGE according to standard procedures. Following electrophoretical separation, using $13 \%$ SDS-PAGE, proteins were transferred to Hybond ${ }^{\mathrm{tm}} \mathrm{ECL}^{\mathrm{tm}}$ nitrocellulose membrane (Amersham) and aspecific binding was blocked in $5 \%(\mathrm{w} / \mathrm{v})$ non fat dry milk (NFDM) for $1 \mathrm{~h}$ at $37^{\circ} \mathrm{C}$ Membranes were incubated with primary antibodies dissolved in PBS/ $5 \%$ NFDM milk for $2 \mathrm{~h}$ at room temperature. Following washing, membranes were incubated with horse radish peroxidase (HRP)conjugated swine anti-rabbit or goat anti-mouse antibodies for $45 \mathrm{~min}$ at room temperature. Protein bands were visualized following $1 \mathrm{~min}$ incubation in enhanced chemiluminescence detection reagents $(E C L)$ and exposure to high performance chemiluminescence film (both purchased from Amersham). All primary antibodies were diluted 1:500 except for the PAb 13666E (1:1000), MAb\#19 (1:1000), and Mab\#C4 $(1: 10000)$. Secondary antibodies were applied in $1: 5000$ dilution.

\section{Acknowledgements}

We would like to thank Hans de Bont and Frans Prins for assisting in confocal laserscan microscopy. The Division of Medical Biochemistry, Sylvius Laboratories, Leiden, is acknowledged for the use of sonification instruments and for advice on subcloning procedures. We thank Joke van Dierendonck-Beukers for critically reading the manuscript and Eduard Bakker for providing the anti-lamin cocktail of antibodies.

\section{References}

1. Adams JM and Cory S (1998) The Bcl-2 protein family: arbiters of cell survival. Science 281: $1322-1326$

2. Reed JC (1998) Bcl-2 family proteins. Oncogene 17: $3225-3236$

3. Tsujimoto Y, Finger LR, Yunis J, Nowell PC and Croce CM (1984) Cloning of the chromosome breakpoint of neoplastic $B$ cells with the $t(14 ; 18)$ chromosome translocation. Science 226: 1097-1099

4. Hockenbery D, Nunez G, Milliman C, Schreiber RD and Korsmeyer SJ (1990) $\mathrm{Bcl}-2$ is an inner mitochondrial membrane protein that blocks programmed cell death. Nature 348: 334-336

5. Oltvai N, Milliman CL and Korsmeyer SJ(1993)Bcl-2 heterodimerizes in vivowith a conserved homolog, Bax, that accelerates programmed cell death. Cell 74 $609-619$

6. Knudson CM and Korsmeyer SJ (1997) Bcl-2 and Bax function independently to regulate cell death. Nat. Genet. 16: 358-363

7. Krajewski S, Tanaka S, Takayama S, Schibler MJ, Fenton W and Reed JC (1993) Investigation of the subcellular distribution of the bcl-2 oncoprotein: residence in the nuclear envelope, endoplasmic reticulum, and outer mitochondrial membranes. Cancer Res. 53: 4701-4714

8. Alnemri ES, Robertson NM, Fernandes TF, Croce CM and Litwack G (1992) Overexpressed full-length human Bcl-2 extends the survival of baculovirusinfected Sf9 insect cells. Proc. Natl. Acad. Sci. USA 89: 7295-7299

9. Monaghan P, Robertson D, Amos TA, Dyer MJ, Mason DY and Greaves MF (1992) Ultrastructural localization of Bcl-2 protein. J. Histochem. Cytochem. 40: $1819-1825$

10. Akao Y, Otsuk Y, Kataoka S, Ito $Y$ and Tsujimoto $Y$ (1994) Muliple subcellular localization of Bcl-2: detection in nuclear outer membrane, endoplasmic reticulum membrane, and mitochondrial membranes. Cancer Res. 54: 24682471

11. Givol I, Tsarfaty I, Rulong S, Pinto daSilva P, Nasioulas G, DuHadaway J, Hughes SH and Evert DL (1994) Bcl-2 expressed using a retroviral vector is localized primarily in the nuclear membrane and the endoplasmic reticulum of chicken embryo fibroblasts. Cell Growth Diff. 5: 419-429

12. DeJong D, Prins FA, Mason DY, Reed JC, VanOmmen GB and Kluin PM (1994) Subcellular localization of the Bcl-2 protein in malignant and normal lymphoid cells. Cancer Res. 54: 256-260 
13. Jacobson MD, Burne JF, King MP, Miyashita T, Reed JC and Raff MC (1993) Bcl2 blocks apoptosis in cells lacking mitochondrial DNA. Nature 361: 365-369

14. Chen-Levy Z, Nourse J and Cleary ML (1989) The bcl-2 candidate protooncogene product is a 24 kilodalton integral-membrane protein highly expressed in lymphoid cell lines and lymphomas carrying the $t(14 ; 18)$ translocation. Mol. Cell Biol. 9: 701-710

15. Nguyen M, Millar DG, Yong WV, Korsmeyer J and Shore GC (1993) Targeting of $\mathrm{Bcl}-2$ to the mitochondrial outer membrane by a $\mathrm{COOH}$-terminal signal anchor sequence. J. Biol. Chem. 268: 25265-25268

16. Borner C, Martinou I, Mattmann C, Irmler M, Schaerer E, Martinou J-C and Tschopp J (1994) The protein Bcl-2 does not require membrane attachment, but two conserved domains to suppress apoptosis. J. Cell Biol. 126: 1059-1068

17. Tanaka S, Saito K and Reed JC (1993) Structure-function analysis of the Bcl-2 oncoprotein. J. Biol. Chem. 268: 10920-10926

18. Zhu W, Cowie A, Wasfy GW, Penn LZ, Leber B and Andrews DW (1996) Bcl-2 mutants with restricted subcellular location reveal spatially distinct pathways for apoptosis in different cell types. EMBO J. 15: 4130-4141

19. Bruel A, Karsenty E, Schmid M, McDonnell TJ and Lanotte M (1997) Altered sensitivity to retinoid-induced apoptosis associated with change in the subcellular distribution of Bcl-2. Exp. Cell Res. 233: 281-287

20. Wolter KG, Hsu Y-T, Smith CL, Nechushtan A, Xi X-G and Youle RJ. (1997) Movement of $B a x$ from the cytosol to mitochondria during apoptosis. J. Cell Biol. 139: $1281-1292$

21. Gross A, JockelJ, Wei MC and Korsmeyer J (1998) Enforced dimerization of Bax results in its translocation, mitochondrial dysfunction and apoptosis. EMBO J. 17: $3878-3885$

22. Goping IS, Gross A, Lavoie JN, Jemmerson R, Roth K, Korsmeyer SJ and Shore GC (1998) Regulated targeting of Bax to mitochondria. J. Cell Biol. 143:207-215

23. Mandal M, Adam L, Mendelsohn J and Kumar R (1998) Nuclear targeting of Bax during apoptosis in human colorectal cancer cells. Oncogene 17: 999-1007

24. Nishita M, Inoue S, Tsuda M, Tateda C and Miyashita T (1998) Nuclear translocation and increased expression of Bax and disturbance in cell cycle progression without prominent apoptosis induced by hyperthermia. Exp. Cell Res. 244: 357-366

25. Ho YS, Lee HM, Chang CR and Lin JK (1999) Induction of Bax protein and degradation of lamin A during p53-dependent apoptosis induced by chemotherapeutic agents in human cancer cell lines. Biochem. Pharmacol. 57: $143-154$

26. Muchmore SW, Sattler M, Liang H, Meadows RP, Harlan JE, Yoon HS, Nettesheim D, Chang BS, Thompson CB, Wong SL, Ng SL and Fesik SW (1996) $\mathrm{X}$-ray and NMR structure of human $\mathrm{Bcl}-\mathrm{X}_{\mathrm{L}}$, an inhibitor of programmed cell death. Nature 381: 335-341

27. Schlesinger PH, Gross A, Yin XM, Yamamoto K, Saito M, Waksman G and Korsmeyer SJ (1997) Comparison of the ion channel characteristics of proapoptotic BAX and antiapoptotic BCL-2. Proc. Natl. Acad. Sci. USA 94: $11357-11362$

28. Antonsson B, Conti F, Ciavatta A, Montessuit S, Lewis S, Martinou I, Bernasconi L, Bernard A, Mermod J-J, Mazzei G, Maudrell K, Gambale F, Sadoulk R and Martinou J-C (1997) Inhibition of Bax channel-forming activity by Bcl-2. Science 277: $370-372$

29. Van Slooten HJ, Clahsen PC, VanDierendonckJH, Duval CH, Pallud C, Mandard A-M, Delobelle-Deroide A, VandeVelde CHJ and VandeVijver MJ (1996) Expression of $\mathrm{Bcl}-2$ in node-negative breast cancer is associated with various prognostic factors, but does not predict response to one course of perioperative chemotherapy. Br. J. Cancer 74: 78-85

30. Lu QL, Hanby AM, Hajibagheri MAN, Gschmeissner SE, Lu P-J, TaylorPapadimitriou JT, Krajewski S, Reed JC and Wright NA (1994) Bcl-2 protein localizes to the chromosomes of mitotic nuclei and is correlated with the cell cycle in cultured epithelial cell lines. J. Cell Sci. 107: 363-371

31. Willingham MC and Bhalla KJ (1994) Transient mitotic phase localization of Bcl-2 oncoprotein in human carcinoma cells and its possible role in prevention of apoptosis. J. Histochem. Cytochem. 42: 441-450
32. Chan WK, Mole MM, Levison DA, Ball RY, Lu Q-L, Patel Kand Hanby AM (1995) Nuclear and cytoplasmic bcl-2 expression in endometrial hyperplasia and adenocarcinoma. Am. J. Pathol. 177: 241-246

33. Paraf F, Gogusev J, Chrétien Y and Droz D (1995) Expression of bcl-2 oncoprotein in renal cell tumours. J. Pathol. 177: 247-252

34. Drachenberg CB, loffe OB, Castellani RJ and Papadimitriou JC (1997) Nuclear Bcl-2 staining in tumors [letter]. Am. J. Clin. Pathol. 108: 479

35. Schandle CA, Li S, Re GG, Fan W and Willingham MC (1999) Mitotic chromosomal Bcl-2: I. Stable expression throughout the cell cycle and association with isolated chromosomes. J. Histochem. Cytochem. 47: 139-149

36. Schandle CA, Li S, Re GG, Fan W and Willingham MC (1999) Mitotic chromosomal Bcl-2: II. Localization to interphase nuclei. J. Histochem. Cytochem. 47: 151-158

37. Teixeira C, Reed JC and Pratt MAC (1995) Estrogen promotes chemotherapeutic drug resistance by a mechanism involving Bcl-2 proto-oncogene expression in human breast cancer cells. Cancer Res. 55: 3902-3907

38. Graham JM and Higgins JA (1993) Methods in Molecular Biology, Volume 19: Biomembrane protocols: I. Isolation and analysis

39. Manilal S, Nguyen TM and Morris GE (1998) Colocalization of emerin and lamins in interphase nuclei and changes during mitosis. Biochem. Biophys. Res. Commun. 249: 643-647

40. Melan Mand Sluder G (1992) Redistribution and differential extraction of soluble proteins in permeabilized cultured cells. J. Cell Science 101: 731-743

41. Ling Y-H, Tornos C and Perez-Sloer R (1998) Phosphorylation of Bcl-2 is a marker of $\mathrm{M}$ phase events and not a determinant of apoptosis. J. Biol. Chem. 273: $18984-18991$

42. Scatena CD, Stewart ZA, Mays D, Tang LJ, Keefer CJ, Leach SD and Pietenpol JA (1998) Mitotic phosphorylation of Bcl-2 during normal cell cycle progression and taxol-induced growth arrest. J. Biol. Chem. 273: 30777-30784

43. Papadimitriou JC, loffe OB, Castellani RJ, Ord RA, Simons J and Drachtenberg CB (1996) Shifting of cytoplasmic pattern of bcl-2 expression in reactive and preneoplastic lesions to nuclear pattern in their malignant counterparts. Cancer Detect. Prev. 2: 529-530A

44. Quignon F, DeBels F, Koken M, Feunteun J, Ameisen J-C and deThé H (1998) PML induces a novel caspase-independent death process. Nat. Genet. 20:259265

45. Quignon F, DeBels F, Koken M, Feunteun J, Ameisen J-C and deThé H (1999) Published erratum in Nat. Genet. 22: 115

46. Rao L, Modha D and White E (1997) The E1B 19K protein associates with lamins in vivo and its proper localization is required for inhibition of apoptosis. Oncogene 15: $1587-1597$

47. Van Slooten H-J, Van de Vijver MJ, Van de Velde CJH and Van Dierendonck JH (1998) Loss of Bcl-2 in invasive breast cancer is associated with high rates of cell death, but also with increased proliferative activity. Br. J. Cancer 77: 789-796

48. Pietenpol JA, Papadopoulos N, Markowitz S, Willson JK, Kinzler KW and Vogelstein B (1994) Paradoxical inhibition of solid tumor cell growth by Bcl-2. Cancer Res. 54: 3714-3717

49. Huang DCS, O'Reilly LA, Strasser A and Cory S (1997) The anti-apoptosis function of $\mathrm{Bcl}-2$ can be genetically separated from an inhibitory effect on cell cycle entry. EMBO J. 16: 4628-4638

50. Gil-Gómez G, Berns A and Brady HJM (1998) A link between cell cycle and cell death: Bax and Bcl-2 modulate Cdk2 activation during thymocyte apoptosis. EMBO J. 17: 7209-7218

51. Takayama S, Xie Z and Reed JC (1999) An evolutionary conserved family of Hsp70/Hsc70 molecular chaperone regulators. J. Biol. Chem. 274: 781 -786

52. Wang J, Moreira KM, Campos B, Kaetzel MA and Dedman JR (1996) Targeted neutralization of calmodulin in the nucleus blocks DNA synthesis and cell cycle progression. Biochim. Biophys. Acta 1313: 223-228

53. Seglen PO (1976) Preparation of isolated rat liver cells. Methods Cell Biol. 13: $29-83$ 